\title{
Cinética de secagem de farinha de grãos residuais de urucum
}

\author{
Dyego da C. Santos ${ }^{1}$, Alexandre J. de M. Queiroz ${ }^{1}$, \\ Rossana M. F. de Figueirêdo ${ }^{1}$ \& Emanuel N. A. de Oliveira ${ }^{1}$
}

\begin{abstract}
RESUMO
O processo de extração do corante bixina produz enorme quantidade de grãos residuais de urucum que vem sendo descartada em grande parte pelas indústrias. Objetivou-se, neste trabalho, desidratar farinhas de grãos residuais de urucum, com e sem a camada de óleo proveniente do processo de extração dos pigmentos em estufa com circulação forçada de ar nas temperaturas de 40, 50, 60 e $70{ }^{\circ} \mathrm{C}$ e ajustar os modelos matemáticos de Aproximação da Difusão, Dois Termos, Midilli, Page e Thompson aos dados experimentais. As farinhas de grãos residuais de urucum com teor de água inicial de aproximadamente $20 \%$ b.u. foram desidratadas até teor de água final de aproximadamente $5 \%$ b.u. Como critério de avaliação do ajuste dos modelos matemáticos utilizaram-se o coeficiente de determinação e o desvio quadrático médio. Verificou-se que as amostras de farinha com óleo demandaram maior intervalo de tempo para atingir o teor de água de $5 \%$ b.u., em comparação com as amostras de farinha sem óleo. Todos os modelos estudados representaram satisfatoriamente a cinética de secagem das farinhas com e sem óleo, com coeficientes de determinação superiores a 0,95 e valores de desvios quadráticos médios inferiores a 1,0.
\end{abstract}

Palavras-chave: Bixa orellana L., subproduto, desidratação, modelagem matemática

\section{Drying kinetics of residual grain flour of annato}

\begin{abstract}
The process of extracting the bixin colorant produces a large amount of residual annatto seeds that, in most cases, has been discarded by the industries. The objective of this study was to dehydrate residual grain flour of annato, with and without the oil layer originated of the extraction process of the pigments in an oven with forced air circulation at 40,50,60 and $70{ }^{\circ} \mathrm{C}$ temperature and to adjust the mathematical models of the Diffusion Approximation, Two Terms, Midilli, Page and Thompson to the experimental data. Residual grain flour of annato with water content approximately $20 \% \mathrm{w} . \mathrm{b}$. was dried to the final water content of about $5 \%$ w.b. As a criterion for evaluating the adjustment of mathematical models the coefficient of determination and mean-square deviation were used. It was found that samples of flour with oil demanded longer time to achieve moisture content of $5 \%$ w.b. in comparison to samples of flour without oil. All studied models accounted satisfactorily drying kinetics of flour with and without oil, with determination coefficients above 0.95 and values of mean-square deviation below 1.0.
\end{abstract}

Key words: Bixa orellana L., byproduct, dehydration, mathematical modeling 


\section{INTRODUÇÃO}

O urucuzeiro (Bixa orellana L.), planta originária da América Tropical, produz frutos ovoides, do tipo cápsulas, contendo em seu interior sementes envolvidas por uma camada avermelhada responsável pela coloração característica; o principal pigmento presente no pericarpo da semente é a bixina que representa mais de $80 \%$ dos carotenoides totais. Este corante é utilizado por indústrias de cosméticos, produtos farmacêuticos e, principalmente, de alimentos, devido à tendência de substituição de corantes sintéticos por naturais.

O processo de extração da bixina produz o grão residual de urucum. Este subproduto apresenta forte coloração vermelha e, na maioria dos casos, uma camada externa de óleo de soja usado como veículo na diluição do pigmento. $\mathrm{O}$ aumento da escala de extração agroindustrial da bixina resulta em 94 a $98 \%$ de sobras que, ao serem descartadas pela indústria, podem poluir o meio ambiente (Silva et al., 2006).

Rêgo et al. (2010) afirmaram que aproximadamente 2.500 t de subproduto do urucum são obtidos no Brasil a cada ano, sobretudo na região Nordeste, onde quase $97 \%$ do subproduto não são aproveitados.

Alguns trabalhos têm sido realizados com a utilização do subproduto constituído pelos grãos residuais de urucum na alimentação animal (Silva et al., 2005; 2006; Rêgo et al., 2010). Segundo Harder et al. (2010) a incorporação de urucum in natura e de seus resíduos industriais na alimentação de animais ruminantes e não ruminantes vem sendo estudada desde 1955. Observa-se então a possibilidade de se direcionar pesquisas com vista ao melhor aproveitamento desses resíduos, inclusive com estudos no sentido de incorporá-los à alimentação humana.

Para estocagem e comercialização de produtos agrícolas é necessário reduzir a quantidade de água do material e consequentemente sua atividade biológica; a secagem surge, então, como o processo mais utilizado para prolongar sua vida útil, por garantir estabilidade durante a armazenagem.

De acordo com Afonso Júnior \& Corrêa (1999) o estudo de sistemas de secagem, seu dimensionamento, otimização e a determinação da viabilidade de sua aplicação comercial, podem ser feitos por simulação matemática. Para a simulação, cujo princípio se fundamenta na secagem de sucessivas camadas do produto, utiliza-se um modelo matemático que representa satisfatoriamente a perda do teor de água do produto durante o período de secagem.

Estão disponíveis na literatura alguns estudos acerca da secagem de sementes in natura de urucum: Guedes \& Faria (2000) determinaram as constantes de secagem de urucum em secador de leito fixo e Faria \& Rocha (2000) secaram sementes de urucum em secador de leito fixo; entretanto, não há registros sobre a secagem de grãos residuais de urucum e de sua farinha.

Ante o exposto e considerando o melhor aproveitamento do subproduto constituído pelos grãos residuais de urucum objetivou-se, neste estudo, desidratar farinhas de grãos residuais de urucum com e sem a camada de óleo proveniente do processo de extração da bixina, em estufa com circulação forçada de ar nas temperaturas de $40,50,60$ e $70{ }^{\circ} \mathrm{C}$ e ajustar diferentes modelos matemáticos aos dados experimentais.

\section{Material e Métodos}

Foram utilizados grãos residuais de urucum doados pela indústria alimentícia Maratá, com sede no Estado de Sergipe. Os grãos residuais de urucum foram recepcionados no laboratório e estocados em recipientes plásticos em temperatura de $-18^{\circ} \mathrm{C}$ até o início dos experimentos; os referidos grãos se apresentavam impregnados de óleo de soja oriundo do processo de extração dos pigmentos.

A manipulação dos grãos residuais de urucum para obtenção das farinhas com a finalidade de realização dos experimentos foi realizada de dois modos, em que no primeiro os grãos foram conservados com a camada de óleo proveniente do processo de extração dos pigmentos e no segundo a camada de óleo foi removida através de lavagem dos grãos em água e com detergente neutro, após o que os grãos residuais foram colocados em bandejas de aço inoxidável e postos em bancada de laboratório com o objetivo de eliminação da água presente na superfície dos grãos.

Os grãos residuais de urucum com e sem óleo foram triturados em moinho de facas obtendo-se as farinhas de grãos residuais de urucum com óleo (FCO) e farinhas de grãos residuais de urucum sem óleo (FSO). Antes do início das secagens o teor de água das amostras de farinhas de grãos residuais de urucum com e sem óleo era de aproximadamente $20 \%$ b.u. ( $25 \%$ b.s.).

Os experimentos de secagem foram realizados com 4 repetições, cada uma foi constituída de aproximadamente 15 $\mathrm{g}$ de amostra, fracionada em recipientes de alumínio (diâmetro de $13,5 \mathrm{~cm}$ e altura de $1,5 \mathrm{~cm}$ ).

Para determinação das cinéticas de secagem as amostras FCO e FSO foram pesadas e conduzidas para secagem em camada fina (espessura de aproximadamente $0,5 \mathrm{~cm}$ ) pelo método em estufa com circulação forçada de ar nas temperaturas de $40,50,60,70{ }^{\circ} \mathrm{C}$ e velocidade do ar de secagem de aproximadamente $1 \mathrm{~m} \mathrm{~s}^{-1}$, em que a perda de água das farinhas de grãos residuais de urucum foi acompanhada até teor de água de aproximadamente $5 \%$ b.u. (5,26\% b.s.).

As amostras foram submetidas a pesagens em tempos regulares de 5, 10, 15, 30, 60, 120 e $240 \mathrm{~min}$. Quando as amostras atingiam o teor de água desejado $(\approx 5 \%$ b.u. $)$, verificado através da diferença entre a massa inicial e final, o teor exato de água era determinado em estufa a $105 \pm 3{ }^{\circ} \mathrm{C}$, até peso constante, de acordo com a metodologia do Instituto Adolfo Lutz (Brasil, 2005) a fim de se calcular os teores finais de água. As razões de água e as curvas de razão de água em função do tempo de secagem foram calculadas e construídas a partir dos dados de perda de massa das amostras durante as secagens e dos teores de água determinados no final das mesmas. No cálculo da razão de água foi utilizada a Eq. 1 .

$$
\mathrm{RX}=\frac{\mathrm{X}-\mathrm{X}_{\mathrm{e}}}{\mathrm{X}_{\mathrm{i}}-\mathrm{X}_{\mathrm{e}}}
$$

em que:

RX - razão de água do produto, adimensional

X - teor de água "absoluto", b.s

$\mathrm{X}_{\mathrm{i}} \quad$ - teor de água inicial do produto, b.s 
$\mathrm{X}_{\mathrm{e}}$ - teor de água de equilíbrio do produto, b.s

Os modelos matemáticos de Aproximação da Difusão, Dois Termos, Midilli, Page e Thompson (Tabela 1) foram ajustados aos dados experimentais oriundos do processo de secagem das farinhas de grãos residuais de urucum com e sem óleo, utilizando-se o programa computacional Statistica 5.0 por meio de análise de regressão não linear, pelo método Quasi-Newton.

Tabela 1. Modelos matemáticos utilizados para predizer o fenômeno de secagem das farinhas de grãos residuais de urucum com e sem óleo

\begin{tabular}{|c|c|c|}
\hline $\begin{array}{l}\text { Designação do } \\
\text { modelo matemático }\end{array}$ & Equação & Referência \\
\hline $\begin{array}{l}\text { Aproximação } \\
\text { da difusão }\end{array}$ & $R X=a \cdot \exp (-k \cdot t)+(1-a) \cdot \exp (-k \cdot b \cdot t$ & (Corrêa et al., 2010) \\
\hline Dois termos & $R X=a \cdot \exp (-k \cdot t)+b \cdot \exp (-q \cdot t)$ & (Jittanit, 2011) \\
\hline Midilli & $R X=a \cdot \exp \left(-k \cdot t^{n}\right)+b \cdot t$ & (Midilli et al., 2002) \\
\hline Page & $R X=\exp \left(-k \cdot t^{n}\right)$ & (Doymaz, 2005) \\
\hline Thompson & $\mathrm{RX}=\exp \left(\left(-\mathrm{a}-\left(\mathrm{a}^{2}+4 \cdot \mathrm{b} \cdot \mathrm{t}\right)^{0,5}\right) / 2 \cdot \mathrm{b}\right)$ & (Sousa et al., 2011) \\
\hline
\end{tabular}

$\mathrm{t}$ - tempo de secagem, min; $\mathrm{k}$ - constante de secagem; $\mathrm{a}, \mathrm{b}, \mathrm{n}, \mathrm{q}$ - coeficientes dos modelos

$\mathrm{Na}$ avaliação da qualidade dos ajustes dos modelos aos dados experimentais foram utilizados, como critério, a análise do coeficiente de determinação $\left(\mathrm{R}^{2}\right)$ e o desvio quadrático médio (DQM) de acordo com a Eq. 2.

$$
\mathrm{DQM}=\sqrt{\frac{\sum\left(\mathrm{RX}_{\text {pred }}-\mathrm{RX}_{\text {exp }}\right)^{2}}{\mathrm{n}}}
$$

em que:

DQM - desvio quadrático médio

$\mathrm{RX}_{\text {pred }}$ - razão de água predito pelo modelo

$\mathrm{RX}_{\mathrm{exp}}$ - razão de água experimental

n - número de observações

\section{Resultados E Discussão}

Verificam-se, na Figura 1, os dados experimentais da cinética de secagem das farinhas dos grãos residuais de

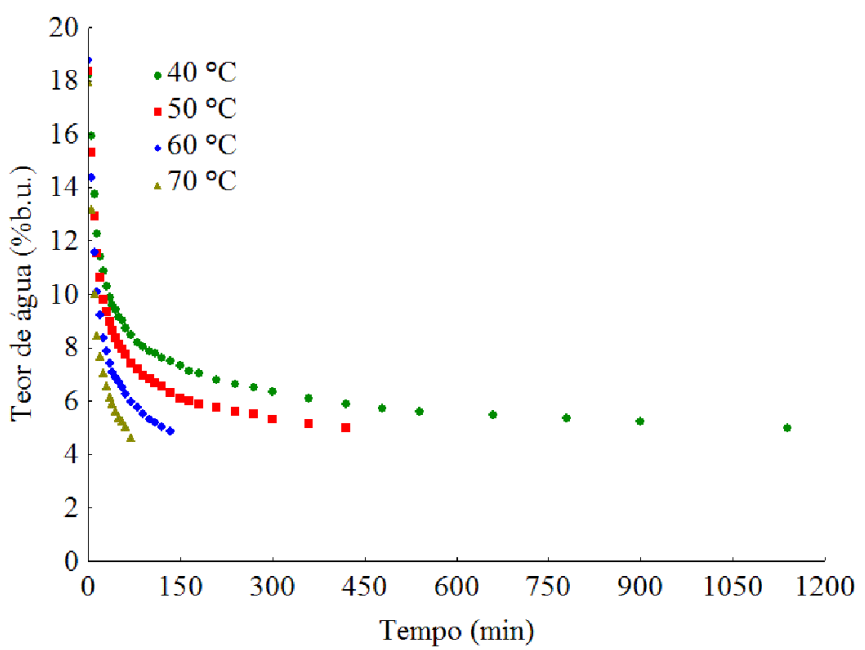

Figura 1. Curvas de secagem da farinha dos grãos residuais de urucum com óleo (FCO) nas temperaturas de $40,50,60$ e $70^{\circ} \mathrm{C}$ urucum com óleo (FCO) nas temperaturas de 40, 50, 60 e 70 ${ }^{\circ} \mathrm{C}$, expressos através do teor de água (\% b.u.) em função do tempo de secagem (min).

Observa-se que o aumento da temperatura promoveu diminuição do teor de água em um tempo menor, comportamento também verificado por Sousa et al. (2006) ao secarem farelo de mamona; Dantas (2007) ao desidratar farinha de amêndoas de jaca; Waughon \& Pena (2008) ao secarem fibra residual do abacaxi, Pena \& Mendonça (2009) ao desidratarem fibra residual do maracujá e Silva \& Viotto (2010) ao secarem resíduos de limão siciliano para obtenção de farinha fibrosa.

Como verificado por Fiorentin et al. (2010) ao estudarem a cinética de secagem de resíduos constituídos por bagaço de laranja, no presente trabalho as curvas de secagem evidenciam que, no intervalo estudado, a influência da temperatura é evidente. Em todas as condições estudadas as curvas de secagem apresentaram uma região linear nos primeiros minutos e em seguida o comportamento passa a ser polinomial. Waughon \& Pena (2006) verificaram comportamento logarítmico nas curvas de secagem após o primeiro momento linear da desidratação de fibra de abacaxi.

As secagens das FCO foram procedidas durante $19 \mathrm{~h}(1140$ min) na temperatura de $40{ }^{\circ} \mathrm{C}, 7 \mathrm{~h}$ ( $420 \mathrm{~min}$ ) na temperatura de $50{ }^{\circ} \mathrm{C}, 2,25 \mathrm{~h}(135 \mathrm{~min})$ na temperatura de $60{ }^{\circ} \mathrm{C}$ e $1,17 \mathrm{~h}(70$ min) na temperatura de $70{ }^{\circ} \mathrm{C}$. O teor de água inicial médio foi de $18,32 \pm 0,34 \%$ b.u. ( $22,43 \%$ b.s.) e o final de $4,87 \pm 0,17 \%$ b.u. $(5,12 \%$ b.s.). Teores de água inferiores variando entre 0,76 e $2,28 \%$ b.s., foram encontrados para a farinha de grãos de abóbora secada em estufa com circulação nas temperaturas entre 40 e $70{ }^{\circ} \mathrm{C}$ (Diógenes, 2010).

Sousa et al. (2006) encontraram, secando farelo de mamona em estufa com ventilação forçada, velocidade do ar de secagem de $1,5 \mathrm{~m} \mathrm{~s}^{-1}$ e espessura da camada de $1 \mathrm{~cm}$, tempos de secagem de $14 \mathrm{~h}$ para a temperatura de $50^{\circ} \mathrm{C}, 9 \mathrm{~h}$ para a temperatura de $60{ }^{\circ} \mathrm{C}$ e $8 \mathrm{~h}$ para as temperaturas de 70 e $80^{\circ} \mathrm{C}$, superiores aos verificados para a secagem das FCO. Pena \& Mendonça (2009) verificaram redução nos tempos de secagem com elevação da temperatura ao secar fibra residual de maracujá nas temperaturas de 50,60 e $70^{\circ} \mathrm{C}$ em secador de leito fixo e velocidade do ar de $2,0 \mathrm{~m} \mathrm{~s}^{-1}$. Costa et al. (2011) encontraram, estudando a secagem de sementes de crambe (Crambe abyssinica) em estufa com circulação forçada de ar, tempos de desidratação de 20,5, 8,5, $5,0,5,0$ e $2,75 \mathrm{~h}$ para as temperaturas de $30,40,50,60$ e 70 ${ }^{\circ} \mathrm{C}$, respectivamente.

Apresentam-se, na Tabela 2, os parâmetros dos ajustes dos modelos matemáticos de Aproximação da Difusão, Dois Termos, Midilli, Page e Thompson, aos dados experimentais da cinética de secagem em estufa com circulação forçada de ar das FCO, seus respectivos coeficientes de determinação $\left(\mathrm{R}^{2}\right)$ e desvios quadráticos médios (DQM).

O modelo matemático de Dois Termos foi o que melhor se ajustou aos dados experimentais da secagem das FCO, apresentando os maiores valores dos coeficientes de determinação $\left(\mathrm{R}^{2}\right)$ superiores a 0,99 , e alguns dos menores valores de DQM (secagem nas temperaturas de 40 e $50^{\circ} \mathrm{C}$ ).

Os modelos matemáticos de Aproximação da Difusão, Midilli, Page e Thompson, também resultaram em bons ajustes aos dados experimentais da secagem das FCO para a 
Tabela 2. Parâmetros dos modelos Aproximação da Difusão, Dois Termos, Midilli, Page e Thompson com seus respectivos coeficientes de determinação $\left(R^{2}\right)$ e desvios quadráticos médios (DQM) da secagem em estufa das farinhas de grãos residuais de urucum com óleo (FCO)

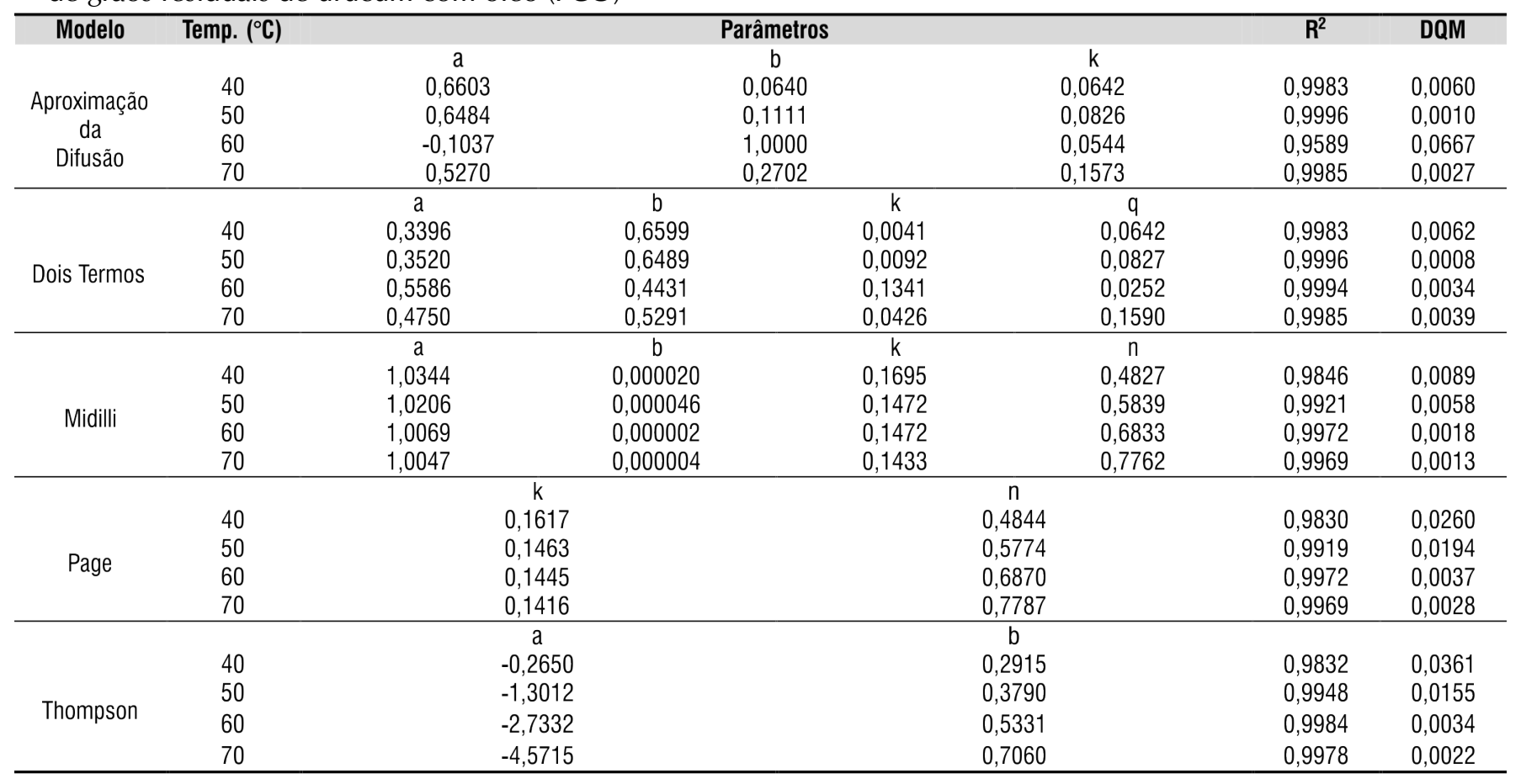

faixa de temperatura estudada, com $\mathrm{R}^{2}$ superiores a 0,98 , com exceção do ajuste para a temperatura de $60{ }^{\circ} \mathrm{C}$ do modelo de Aproximação da Difusão, em que o $\mathrm{R}^{2}$ foi maior que 0,95 . Todos os modelos avaliados também apresentaram baixos valores de DQM podendo ser utilizados na predição da cinética de secagem das farinhas dos grãos residuais de urucum com a camada de óleo.

Meziane (2011) também encontrou valores de coeficientes de determinação $\left(\mathrm{R}^{2}\right)$ superiores a 0,99 , para a faixa de temperatura de 40 a $50^{\circ} \mathrm{C}$, ao ajustar o modelo de Dois Termos aos dados experimentais da secagem do resíduo de azeitona.

Sousa et al. (2006) constataram coeficientes de determinação $\left(\mathrm{R}^{2}\right)$ superiores a 0,99 , para os modelos matemáticos de Page e Thompson, ao estudar a cinética de secagem do farelo de mamona nas temperaturas de $50,60,70$ e $80^{\circ} \mathrm{C}$, com espessura da camada de farinha de 1,0,3,0 e 5,0 cm e velocidade do ar de secagem de $1 \mathrm{~m} \mathrm{~s}^{-1}$, estando de acordo com os resultados verificados nas secagens das FCO para a faixa de temperatura de 50 a $70^{\circ} \mathrm{C}$.

Waughon \& Pena (2008) encontraram ajustes superiores a 0,99 para os modelos de Aproximação da Difusão, Dois Termos, Midilli e Page, ao desidratar a fibra residual de abacaxi nas temperaturas de 50,60 e $70^{\circ} \mathrm{C}$ e velocidades do ar de secagem de $2,0,2,5$ e $3,0 \mathrm{~m} \mathrm{~s}^{-1}$.

Diógenes (2010) observou coeficientes de determinação $\left(\mathrm{R}^{2}\right)$ superiores a 0,99 para os modelos de Aproximação da Difusão e Page e baixos valores de DQM, durante a avaliação da cinética de secagem da farinha de grãos de abóbora nas temperaturas de $40,50,60,70$ e $80{ }^{\circ} \mathrm{C}$ e velocidade do ar de secagem de aproximadamente $1,0 \mathrm{~m} \mathrm{~s}^{-1}$. Dantas (2007) verificou, para o modelo de Page, ajustes superiores a 0,99 ao secar amêndoas de jaca moídas nas temperaturas de $40,50,60,70$ e $80^{\circ} \mathrm{C}$.
O parâmetro " $\mathrm{k}$ " dos modelos matemáticos de Midilli e Page diminuiu com a elevação da temperatura de secagem; no entanto, verifica-se que este parâmetro aumentou para o modelo de Dois Termos, para a faixa de temperatura de 40 a $60{ }^{\circ} \mathrm{C}$; observa-se ainda que o parâmetro "n" dos modelos de Midilli e Page aumentou com o aumento da temperatura; comportamento semelhante também foi verificado por Doymaz (2005) que, ao ajustar o modelo de Page aos dados experimentais da secagem de feijão verde nas temperaturas de 50 a $70{ }^{\circ} \mathrm{C}$ observou diminuição no parâmetro "k". Sousa et al. (2006) também verificaram elevação no parâmetro " $\mathrm{n}$ " para o modelo de Page, ao desidratar farelo de mamona. Pacheco et al. (2011) secaram cogumelos nas temperaturas de $50,60,70$ e $80^{\circ} \mathrm{C}$ e velocidades do ar de 1,5, 2,5 e 3,5 $\mathrm{m} \mathrm{s}^{-1} \mathrm{e}$ constataram que, para a velocidade do ar de $1,5 \mathrm{~m} \mathrm{~s}^{-1}$, o modelo de Page também teve o parâmetro "n" aumentado com a elevação da temperatura de secagem. Jittanit (2011) ajustou o modelo de Page aos dados experimentais da secagem de sementes de abóbora em secador de bandejas nas temperaturas de 60,70 e $80{ }^{\circ} \mathrm{C}$ e observou comportamento contrário, visto que o parâmetro " $n$ " diminuiu com a elevação da temperatura de secagem.

De acordo com Corrêa et al. (2010) o parâmetro "k" tende a aumentar visto que maiores temperaturas acarretam maiores taxas de secagem chegando ao teor de água de equilíbrio em menor tempo de submissão do produto ao ar de secagem (Corrêa et al., 2010). Guedes \& Faria (2000) quantificaram, a partir dos resultados da constante de secagem "k", do modelo de Page, o efeito da temperatura sobre este parâmetro.

O parâmetro " $n$ " possui um efeito de moderação do tempo e corrige os prováveis erros resultantes da negligência da resistência interna para a transferência de água (Guedes \& Faria, 2000). 
O parâmetro "b" do modelo de Thompson aumentou com a elevação da temperatura de secagem. Para o modelo de Aproximação da Difusão, o parâmetro "b" aumentou com a elevação da temperatura para a faixa de temperatura de 40 a $60{ }^{\circ} \mathrm{C}$; observou-se, entretanto, comportamento inverso para este parâmetro no modelo de Dois Termos, para a faixa de temperatura de 40 a $60{ }^{\circ} \mathrm{C}$ cuja elevação da temperatura promoveu redução no parâmetro "b". Sousa et al. (2006) também verificaram, secando farelo de mamona com espessura de 3,0 cm, aumento no parâmetro "b" do modelo de Thompson com a elevação da temperatura de secagem.

O parâmetro "a" dos modelos de Midilli e Thompson diminui com a elevação da temperatura. No modelo de Dois Termos tornou-se notório que o parâmetro "a" aumentou com a elevação da temperatura para a faixa de temperatura de 40 a 60 ${ }^{\circ} \mathrm{C}$, comportamento também verificado por Lema et al. (2007) que desidrataram salsa nas temperaturas de $35,45,55$ e $65^{\circ} \mathrm{C}$ e velocidade do ar de secagem de $1,0 \mathrm{~m} \mathrm{~s}^{-1}$.

Observa-se, na Tabela 3, a tendência de distribuição de resíduos para os modelos ajustados aos dados experimentais da secagem da farinha de grãos residuais de urucum com óleo nas temperaturas de 40 a $70{ }^{\circ} \mathrm{C}$. Pode-se verificar que o modelo de Dois Termos apresentou distribuição aleatória para todas as condições de secagem resultando em melhor ajuste para a cinética das amostras FCO. Este modelo foi considerado aleatório uma vez que os valores residuais não formaram figuras definidas, não indicando tendenciosidade dos resultados.

Tabela 3. Tendência de distribuição de resíduos para os modelos ajustados aos pontos experimentais da cinética de secagem da farinha de grãos residuais de urucum com óleo (FCO)

\begin{tabular}{lllll}
\hline \multirow{2}{*}{ Modelo } & \multicolumn{4}{c}{ Temperatura $\left({ }^{\circ} \mathbf{C}\right)$} \\
\cline { 2 - 5 } Aproximação da Difusão & Aleatório & Aleatório & Tendencioso & Aleatório \\
Dois Termos & Aleatório & Aleatório & Aleatório & Aleatório \\
Midilli & Tendencioso & Tendencioso & Aleatório & Tendencioso \\
Page & Tendencioso & Tendencioso & Aleatório & Tendencioso \\
Thompson & Tendencioso & Tendencioso & Aleatório & Tendencioso \\
\hline
\end{tabular}

Pode-se verificar, na Figura 2, as curvas geradas pelos ajustes do modelo matemático de Dois Termos aos dados experimentais da cinética de secagem das FCO para as temperaturas de secagem de $40,50,60$ e $70{ }^{\circ} \mathrm{C}$. Conforme o conjunto de valores de coeficientes de determinação $\left(\mathrm{R}^{2}\right) \mathrm{e}$ DQM, este modelo matemático foi o melhor para estimar as curvas de cinética de secagem das FCO.

$\mathrm{Na}$ Figura 3 se apresenta o gráfico de razão de teor de água (RX), experimentais e estimados, referente à equação de Dois Termos, da cinética de secagem das amostras FCO nas temperaturas de $40,50,60$ e $70{ }^{\circ} \mathrm{C}$. Nota-se, para todas as temperaturas estudadas, que o modelo em questão teve bom ajuste na descrição do fenômeno de secagem. De acordo com Afonso Júnior \& Corrêa (1999) a dispersão dos dados experimentais em relação aos dados estimados indica ajustamento da equação de secagem.

$\mathrm{Na}$ Figura 4 se encontram os dados experimentais da cinética de secagem das farinhas dos grãos residuais de urucum sem óleo (FSO) nas temperaturas de 40, 50, 60 e 70

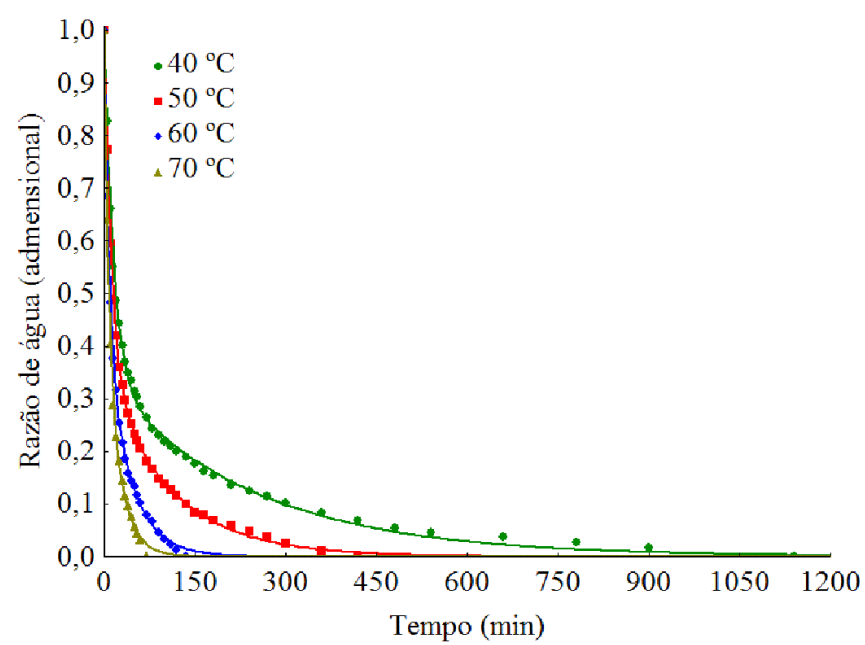

Figura 2. Modelo de Dois Termos ajustado à cinética de secagem da farinha dos grãos residuais de urucum com óleo (FCO)

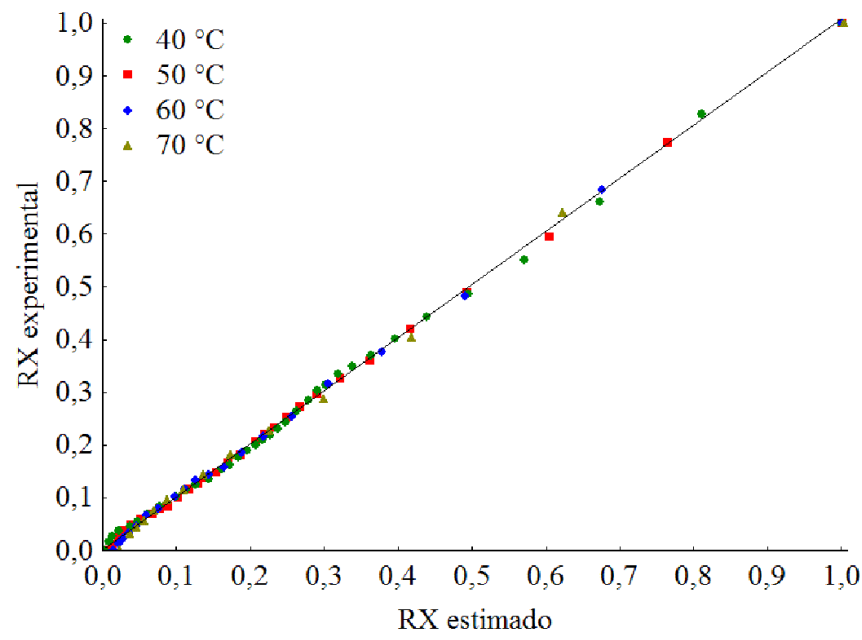

Figura 3. Relação entre os valores experimentais e estimados de razão de teor de água pela equação de Dois Termos para a cinética de secagem de farinha de grãos residuais de urucum com óleo (FCO) nas temperaturas de $40,50,60$ e $70{ }^{\circ} \mathrm{C}$

${ }^{\circ} \mathrm{C}$, expressos através do teor de água (\% b.u.) em função do tempo de secagem (min). Observam-se reduções nos teores de água com a elevação da temperatura de secagem promovendo diminuição nos tempos de desidratação. As secagens das FSO foram levadas a efeito nos tempos de $15 \mathrm{~h}$ (900 $\mathrm{min}), 6 \mathrm{~h}$ (360 $\mathrm{min}), 1,83 \mathrm{~h}$ (110 $\mathrm{min})$ e $0,83 \mathrm{~h}$ (50 $\mathrm{min}$ ) para as temperaturas de $40,50,60$ e $70{ }^{\circ} \mathrm{C}$, em que o teor de água inicial médio foi de $20,95 \pm 0,71 \%$ b.u. $(26,50 \%$ b.s. $)$ e o final de $4,92 \pm$ $0,04 \%$ b.u. $(5,17 \%$ b.s. $)$.

Rafiee et al. (2009) secaram grãos de soja nas temperaturas de $30,40,50,60$ e $70^{\circ} \mathrm{C}$ e também observaram reduções mais bruscas nas razões de água dos grãos que foram desidratados nas temperaturas mais elevadas.

Ferreira \& Pena (2010) desidrataram cascas residuais de maracujá amarelo em estufa nas temperaturas de 60,70 e 80 ${ }^{\circ} \mathrm{C}$ e também verificaram redução nos tempos de secagem com o aumento da temperatura. Esses autores encontraram tempos de secagem de aproximadamente $600 \mathrm{~min}(10,00 \mathrm{~h}), 530 \mathrm{~min}$ 


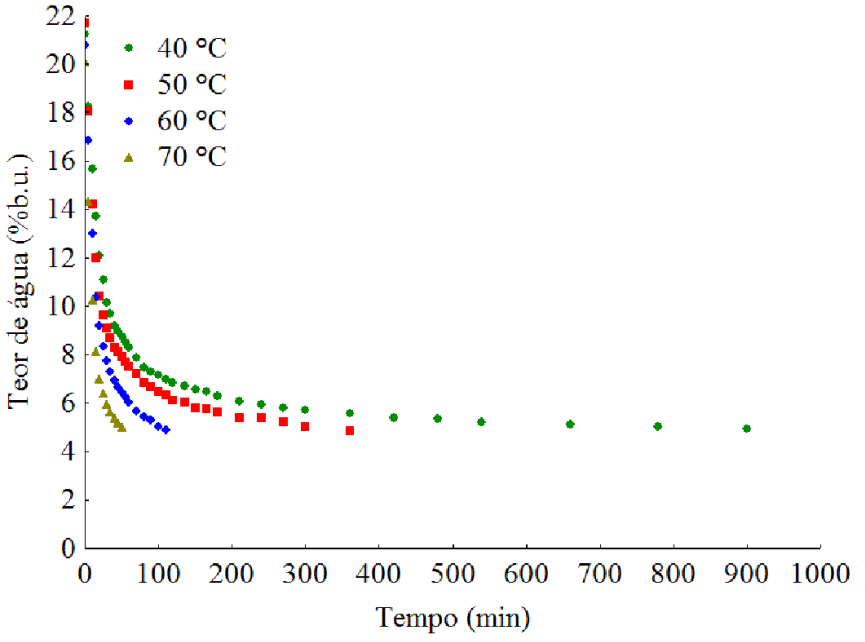

Figura 4. Curvas de secagem da farinha dos grãos residuais de urucum sem (FSO) óleo nas temperaturas de $40,50,60$ e $70^{\circ} \mathrm{C}$

$(8,80 \mathrm{~h})$ e $475 \mathrm{~min}(7,90 \mathrm{~h})$ para as temperaturas de 60,70 e 80 ${ }^{\circ} \mathrm{C}$, respectivamente, tempos esses superiores aos verificados nas secagens das FSO.

Botelho et al. (2011) observaram, secando fatias de cenoura nas temperaturas de 50, 60, 70, 80, 90 e $100{ }^{\circ} \mathrm{C}$, redução nos tempos de desidratação com a elevação da temperatura de secagem.

Luangmalawat et al. (2008) secaram arroz e verificaram tempos de secagem de $360,270,120,90$ e 70 min para as temperaturas de secagem de $50,60,80,100$ e $120^{\circ} \mathrm{C}$, respectivamente, além de velocidade do ar de $0,4 \mathrm{~m} \mathrm{~s}^{-1}$.

Pontes et al. (2009) verificaram, desidratando pimenta de cheiro em camada delgada em secador estacionário tipo cabine nas temperaturas de 50,60 e $70{ }^{\circ} \mathrm{C}$ e velocidade do ar de secagem de $1,5 \mathrm{~m} \mathrm{~s}^{-1}$, tempos de secagem de 10, 2,7 e 2,3 $\mathrm{h}$, para as temperaturas de 50,60 e $70^{\circ} \mathrm{C}$, respectivamente.

Comparando os tempos de secagem das amostras FSO e FCO verifica-se que os menores tempos de secagem foram encontrados nas amostras FSO evidenciando o efeito do óleo no aumento dos tempos de secagem das amostras.

$\mathrm{Na}$ Tabela 4 se apresentam os parâmetros dos ajustes dos modelos matemáticos de Aproximação da Difusão, Dois Termos, Midilli, Page e Thompson, aos dados experimentais da cinética de secagem em estufa com circulação forçada de ar das FSO com respectivos coeficientes de determinação $\left(\mathrm{R}^{2}\right)$ e desvios quadráticos médios (DQM).

Observa-se que o modelo matemático de Dois Termos foi o que melhor se ajustou aos dados experimentais da secagem das FSO apresentando valores de coeficientes de determinação $\left(\mathrm{R}^{2}\right)$ superiores a $0,99 \mathrm{e}$ alguns dos mais baixos valores de DQM (secagem nas temperaturas de 40 a $60^{\circ} \mathrm{C}$ ).

Os modelos matemáticos de Aproximação da Difusão, Midilli, Page e Thompson, também apresentaram bons ajustes aos dados experimentais da secagem das FSO para a faixa de temperatura de 40 a $70{ }^{\circ} \mathrm{C}$, com coeficientes de determinação $\left(\mathrm{R}^{2}\right)$ superiores a 0,98 e valores baixos de DQM $(\leq 0,0531)$ podendo ainda ser utilizados na predição da cinética de secagem das farinhas dos grãos residuais de urucum sem óleo (FSO); para a faixa de temperatura de 60 a $70^{\circ} \mathrm{C}$ esses modelos matemáticos apresentaram ajustes com $\mathrm{R}^{2}$ superiores a 0,99 .

Dantas (2007) e Pontes et al. (2009) obtiveram coeficientes de determinação superiores a 0,99 aos ajustar o modelo de Page aos dados experimentais das secagens de farinha de amêndoas de jaca e pimenta de cheiro, respectivamente.

Costa et al. (2011) secaram sementes de crambe com teor de água inicial de 0,26 (decimal b.s.) nas temperaturas de 30, 40,

Tabela 4. Parâmetros dos modelos Aproximação da Difusão, Dois Termos, Midilli, Page e Thompson com seus respectivos coeficientes de determinação $\left(R^{2}\right)$ e desvios quadráticos médios (DQM) da secagem em estufa das farinhas de grãos residuais de urucum sem óleo (FSO)

\begin{tabular}{|c|c|c|c|c|c|c|c|}
\hline Modelo & Temp. $\left({ }^{\circ} \mathrm{C}\right)$ & \multicolumn{4}{|c|}{ Parâmetros } & $\mathbf{R}^{2}$ & DQM \\
\hline Dois Termos & $\begin{array}{l}40 \\
50 \\
60 \\
70 \\
\end{array}$ & $\begin{array}{c}\mathrm{a} \\
0,7670 \\
0,2673 \\
0,2880 \\
0,5008\end{array}$ & $\begin{array}{c}\mathrm{b} \\
0,2406 \\
0,7520 \\
0,7298 \\
0,5008 \\
\end{array}$ & $\begin{array}{c}\mathrm{k} \\
0,0592 \\
0,0101 \\
0,0256 \\
0,1004 \\
\end{array}$ & $\begin{array}{c}q \\
0,0057 \\
0,0867 \\
0,0939 \\
0,1004\end{array}$ & $\begin{array}{l}0,9992 \\
0,9978 \\
0,9966 \\
0,9987\end{array}$ & $\begin{array}{l}0,0035 \\
0,0011 \\
0,0038 \\
0,0076\end{array}$ \\
\hline Midilli & $\begin{array}{l}40 \\
50 \\
60 \\
70 \\
\end{array}$ & $\begin{array}{c}\mathrm{a} \\
1,0367 \\
1,0267 \\
1,0149 \\
1,0028 \\
\end{array}$ & $\begin{array}{c}b \\
0,000034 \\
0,000088 \\
0,000176 \\
0,000157\end{array}$ & $\begin{array}{c}\mathrm{k} \\
0,1305 \\
0,1449 \\
0,0944 \\
0,1000 \\
\end{array}$ & $\begin{array}{c}\mathrm{n} \\
0,6119 \\
0,6438 \\
0,8595 \\
1,0063 \\
\end{array}$ & $\begin{array}{l}0,9845 \\
0,9838 \\
0,9929 \\
0,9988 \\
\end{array}$ & $\begin{array}{l}0,0207 \\
0,0114 \\
0,0045 \\
0,0014 \\
\end{array}$ \\
\hline Page & $\begin{array}{l}40 \\
50 \\
60 \\
70 \\
\end{array}$ & & & & & $\begin{array}{l}0,9818 \\
0,9812 \\
0,9920 \\
0,9987 \\
\end{array}$ & $\begin{array}{l}0,0531 \\
0,0373 \\
0,0194 \\
0,0065\end{array}$ \\
\hline Thompson & $\begin{array}{l}40 \\
50 \\
60 \\
70\end{array}$ & & & & & $\begin{array}{l}0,9885 \\
0,9877 \\
0,9949 \\
0,9988\end{array}$ & $\begin{array}{l}0,0454 \\
0,0312 \\
0,0092 \\
0,0030\end{array}$ \\
\hline
\end{tabular}


50,60 e $70{ }^{\circ} \mathrm{C}$, até teor de 0,09 (decimal b.s.) e verificaram que os modelos de Aproximação da Difusão, Dois Termos, Midilli, Page e Thompson produziram ajustes com $\mathrm{R}^{2}$ superiores a 0,99 .

Lema et al. (2007) também observaram coeficientes de determinação $\left(R^{2}\right)$ superiores a 0,99 para os modelos matemáticos de Dois Termos, Midilli e Page, ao ajustar os dados experimentais da cinética de secagem de salsa nas temperaturas de $35,45,55$ e $65{ }^{\circ} \mathrm{C}$ e velocidade do ar de secagem $1 \mathrm{~m} \mathrm{~s}^{-1}$. Referidos autores verificaram, para o modelo de Aproximação da Difusão, ajuste superior a 0,99 para a faixa de temperatura de 45 a $65^{\circ} \mathrm{C}$.

Observa-se que o parâmetro "k" do modelo de Aproximação da Difusão aumentou com a elevação da temperatura. Os parâmetros " $n$ " dos modelos matemáticos de Page e Midilli aumentaram com o aumento de temperatura de secagem. Rafiee et al. (2009) observaram, ajustando o modelo de Page aos dados experimentais da secagem de grãos de soja, aumento nos parâmetros "a" e "n" da equação.

Os parâmetros "a" dos modelos de Aproximação da Difusão, Midilli e Thompson diminuíram com o aumento da temperatura do ar de secagem. Rafiee et al. (2009) observaram, ao desidratar grãos de soja nas temperaturas de $30,40,50,60$ e $70{ }^{\circ} \mathrm{C}$, que o parâmetro "a" do modelo de Aproximação da Difusão aumentou com a elevação da temperatura de secagem para a faixa de temperatura de $30 \mathrm{a} 60^{\circ} \mathrm{C}$. No tocante ao parâmetro "b" dos modelos de Midilli (faixa de temperatura de 40 a $60^{\circ} \mathrm{C}$ ), Aproximação da Difusão e Thompson verificam-se aumentos no mesmo com a elevação da temperatura de secagem. Pode-se notar ainda que o paramento "q" do modelo de Dois Termos também aumentou com a elevação da temperatura de secagem, comportamento igualmente verificado por Jittanit (2011) ao desidratar sementes de abóbora em secador de bandejas nas temperaturas de 60,70 e $80^{\circ} \mathrm{C}$.

Pode-se observar, na Tabela 5, a tendência de distribuição de resíduos para os modelos ajustados aos dados experimentais da secagem da farinha de grãos residuais de urucum sem óleo nas temperaturas de 40 a $70^{\circ} \mathrm{C}$; tal como verificado para as amostras FCO, observou-se comportamento aleatório dos resíduos para todas as temperaturas estudadas para o modelo de Dois Termos.

Tabela 5. Tendência de distribuição de resíduos para os modelos ajustados aos pontos experimentais da cinética de secagem da farinha de grãos residuais de urucum sem óleo (FSO)

\begin{tabular}{lllll}
\hline \multirow{2}{*}{ Modelo } & \multicolumn{4}{c}{ Temperatura $\left({ }^{\circ} \mathbf{C}\right)$} \\
\cline { 2 - 5 } Aproximação da Difusão & Aleatório & Aleatório & Tendencioso & Aleatório \\
Dois Termos & Aleatório & Aleatório & Aleatório & Aleatório \\
Midilli & Tendencioso & Tendencioso & Tendencioso & Aleatório \\
Page & Tendencioso & Tendencioso & Tendencioso & Aleatório \\
Thompson & Tendencioso & Tendencioso & Tendencioso & Aleatório \\
\hline
\end{tabular}

As curvas de ajuste do modelo matemático de Dois Termos aos dados experimentais da cinética de secagem das FSO para as temperaturas de secagem de $40,50,60$ e $70^{\circ} \mathrm{C}$, são apresentadas na Figura 5. De acordo com os valores dos coeficientes de determinação $\left(\mathrm{R}^{2}\right)$ e $\mathrm{DQM}$, este modelo matemático foi o melhor para se estimar as curvas de cinética de secagem das FSO.

Observa-se, na Figura 6, o gráfico de razão de teor de água (RX) experimentais e estimados, referente à equação de

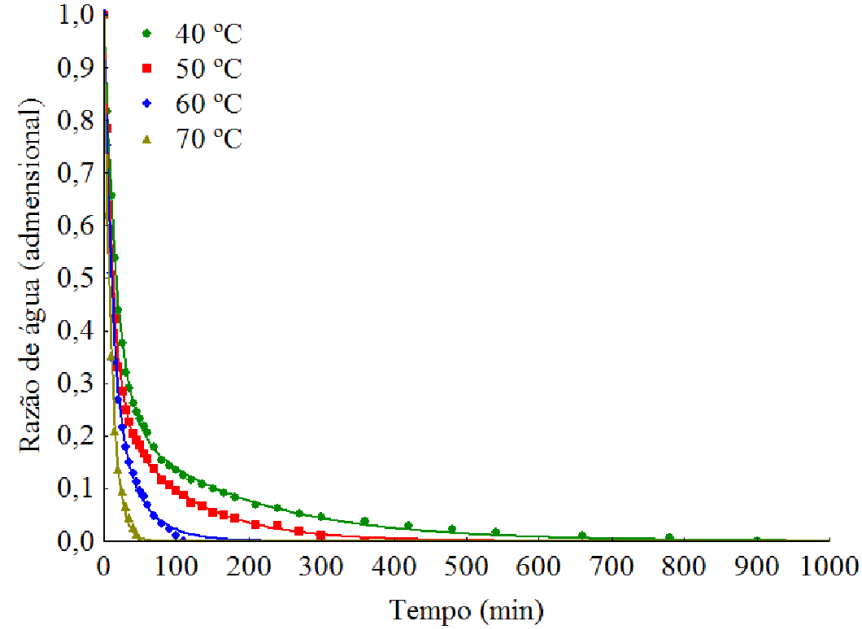

Figura 5. Modelo de Dois Termos ajustado à cinética de secagem da farinha dos grãos residuais de urucum sem óleo (FSO)

Dois Termos, da cinética de secagem das amostras FSO nas temperaturas de $40,50,60$ e $70^{\circ} \mathrm{C}$; tal como constatado para a secagem das amostras FCO, o modelo de Dois Termos teve bom ajuste na descrição do fenômeno de secagem, para todas as temperaturas estudadas. Sousa et al. (2011) verificaram, para o modelo de Midilli, que com a redução dos valores da razão de teor de água ocorre maior discrepância entre os valores experimentais e estimados pelo modelo, fenômeno não observado na secagem das amostras FSO.

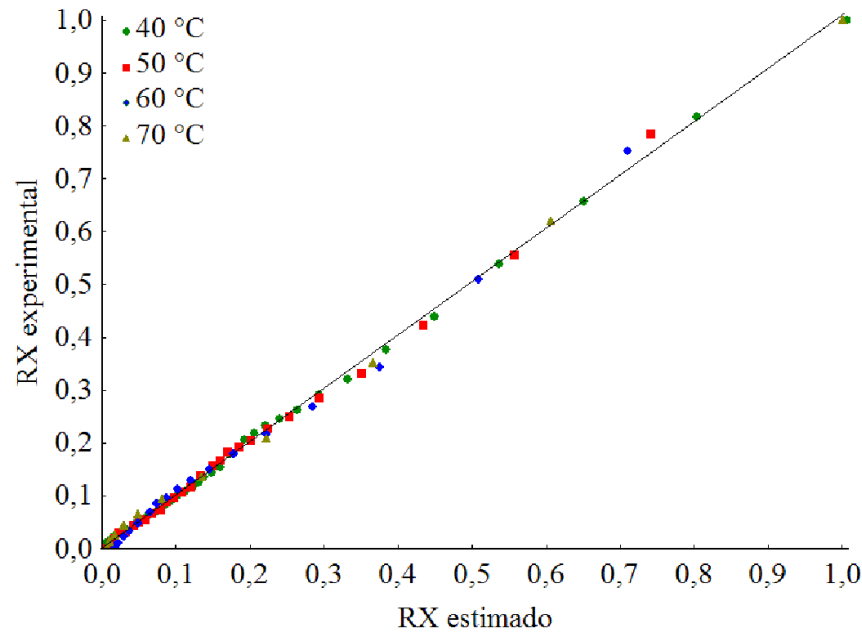

Figura 6. Relação entre os valores experimentais e estimados de razão de teor de água pela equação de Dois Termos para a cinética de secagem de farinha de grãos residuais de urucum sem óleo (FSO) nas temperaturas de $40,50,60$ e $70{ }^{\circ} \mathrm{C}$

\section{Conclusões}

1. O aumento na temperatura de secagem promoveu redução nos tempos de desidratação.

2. Para todas as temperaturas estudadas as amostras de farinha com óleo demandaram maior tempo de secagem para atingir o teor de água de $5 \%$ b.u., em comparação com as amostras de farinha sem óleo. 
3. Todos os modelos estudados representaram satisfatoriamente a cinética de secagem das farinhas de grãos residuais de urucum com e sem óleo, com coeficientes de determinação superiores a 0,95 e baixos valores dos desvios quadráticos médios (DQM).

4. Dentre os modelos de secagem estudados o modelo de Dois Termos apresentou os maiores valores dos coeficientes de determinação e alguns dos menores valores de DQM, para ambas as farinhas pesquisadas.

\section{Agradecimentos}

Ao Conselho Nacional de Desenvolvimento Científico e Tecnológico (CNPq) e à Coordenação de Aperfeiçoamento de Pessoal de Nível Superior (CAPES) pelo apoio financeiro essencial para o desenvolvimento deste trabalho e à indústria alimentícia Maratá, pela doação dos grãos residuais de urucum.

\section{Literatura Citada}

Afonso Júnior, P. C.; Corrêa, P. C. Comparação de modelos matemáticos para descrição da cinética de secagem em camada fina de sementes de feijão. Revista Brasileira de Engenharia Agrícola e Ambiental, v.3, p.349-353, 1999.

Botelho, F. M.; Corrêa, P. C.; Goneli, A. L. D.; Martins, M. A.; Magalhães, F. E. A.; Campos, S.C. Periods of constant and falling-rate for infrared drying of carrot slices. Revista Brasileira de Engenharia Agrícola e Ambiental, v.15, p.845852, 2011.

Brasil. Ministério da Saúde. Agência Nacional de Vigilância Sanitária. Métodos físico-químicos para análises de alimentos. Brasília: Ministério da Saúde, 2005. 1017p.

Corrêa, P. C.; Oliveira, G. H. H.; Botelho, F. M.; Goneli, A. L. D.; Carvalho, F. M. Modelagem matemática e determinação das propriedades termodinâmicas do café (Coffea arabica L.) durante o processo de secagem. Revista Ceres, v.57, p.595-601, 2010.

Costa, L. M.; Resende, O.; Sousa, K. A.; Gonçalves, D. N. Coeficiente de difusão efetivo e modelagem matemática da secagem de sementes de crambe. Revista Brasileira de Engenharia Agrícola e Ambiental, v.15, p.1089-1096, 2011.

Dantas, H. J. Secagem solar e convencional de amêndoas de jaca. Campina Grande: UFCG, 2007. 125p. Dissertação Mestrado

Diógenes, A. M. G. Secagem solar e convencional de grãos de abóbora. Campina Grande: UFCG, 2010. 155p. Dissertação Mestrado

Doymaz, I. Drying behaviour of green beans. Journal of Food Engineering, v.69, p.161-165, 2005.

Faria, L. J. G.; Rocha, S. C. S. Optimization of annatto (Bixa orellana L.) drying in fixed bed. Brazilian Journal of Chemical Engineering, v.17, p.483-496, 2000.

Ferreira, M. F. P.; Pena, R. S. Estudo da secagem da casca do maracujá amarelo. Revista Brasileira de Produtos Agroindustriais, v.12, p.15-28, 2010.

Fiorentin, L. D.; Menon, B. T.; Alves, J. A.; Barros, S. T. D.; Pereira, N. C.; Módenes, A.N. Determinação da cinética e das isotermas de secagem do bagaço da laranja. Acta Scientiarum. Technology, v.32, p.147-152, 2010.
Guedes, A. M. M.; Faria, L. J. G. Determinação da constante de secagem de urucum (Bixa orellana L.) em secador convectivo de leito fixo. Revista Brasileira de Produtos Agroindustriais, v.2, p.73-86, 2000.

Harder, M. N. C.; Spada, F. P.; Savino, V. J. M.; Coelho, A. A. D.; Correr, E.; Martins, E. Coloração de cortes cozidos de frangos alimentados com urucum. Ciência e Tecnologia de Alimentos, v.30, p.507-509, 2010.

Jittanit, W. Kinetics and temperature dependent moisture diffusivities of pumpkin seeds during drying. Kasetsart Journal: Natural Science, v.45, p.147-158, 2011.

Lema, A.; Pontin, M.; Sanmartino, A.; Ziletti, M.; Martinello, M. Características del proceso de secado en capa delgada del perejil. Avances en Energías Renovables y Medio Ambiente, v.11, p.875-882, 2007.

Luangmalawat, P.; Prachayawarakornb, S.; Nathakaranakulea, A.; Soponronnarita, S. Effect of temperature on drying characteristics and quality of cooked rice. Food Science and Technology, v.41, p.716-723, 2008.

Meziane, S. Drying kinetics of olive pomace in a fluidized bed dryer. Energy Conversion and Management, v.52, p.16441649, 2011.

Midilli, A.; Kucuk, H.; Yapar, Z. A new model for single layer drying. Drying Technology, v.20, p.1503-1513, 2002.

Pacheco, A. C. W.; Luz, G. R.; Polon, P. E.; Jorge, L. M. M.; Paraíso, P. R. Modeling of drying and adsorption isotherms of the fish feed. Brazilian Archives of Biology and Technology, v.54, p.577-588, 2011.

Pena, R. S.; Mendonça, N. B. Secagem em camada delgada da fibra residual do maracujá. Boletim do Centro de Pesquisa de Processamento de Alimentos, v.27, p.257-270, 2009.

Pontes, S. F. O.; Santos, C. T.; Bonomo, R. C. F.; Pontes, L. V.; Fontan, R. C. I. Determinação das curvas de secagem em camada delgada de pimenta de cheiro (Capsicum chinense) a diferentes temperaturas Revista Brasileira de Produtos Agroindustriais, v.11, p.143-148, 2009.

Rafiee, S. H.; Keyhani, A.; Sharifi, M.; Jafari, A.; Mobli, H.; Tabatabaeefar, A. Thin layer drying properties of soybean (Viliamz Cultivar). Journal of Agricultural Science and Technology, v.11, p.289-300, 2009.

Rêgo, A. C.; Cândido, M. J. D.; Pereira, E. S.; Feitosa, J. V.; Rêgo, M. M. T. Degradação de silagens de capimelefante contendo subproduto do urucum. Revista Ciência Agronômica, v.41, p.482-489, 2010.

Silva, J. H. V.; Silva, E. L.; Jordão Filho, J.; Ribeiro, M. L. G. Efeitos da inclusão do resíduo da semente de urucum (Bixa orellana L.) na dieta para frangos de corte: Desempenho e características de carcaça. Revista Brasileira de Zootecnia, v.34, p.1606-1613, 2005.

Silva, J. H. V.; Silva, E. L.; Jordão Filho, J.; Ribeiro, M. L. G.; Costa, F. G. P. Resíduo da semente de urucum (Bixa orellana L.) como corante da gema, pele, bico e ovário de poedeiras avaliado por dois métodos analíticos. Ciência e Agrotecnologia, v.30, p.988-994, 2006.

Silva, V. M.; Viotto, L. A. Drying of sicilian lemon residue: influence of process variables on the evaluation of the dietary fiber produced. Ciência e Tecnologia de Alimentos, v.30, p.421-428, 2010. 
Sousa, K. A.; Resende, O.; Chaves, T. H.; Costa, L. M. Cinética de secagem do nabo forrageiro (Raphanus sativus L.). Revista Ciência Agronômica, v.42, p.883-892, 2011.

Sousa, M. B.; Pedroza, J. P.; Beltrão, N. E. de M.; Severino, L. S.; Dantas, F. P. Cinética de secagem do farelo de mamona. Revista Brasileira de Produtos Agroindustriais, v.8, p.135146, 2006.
Waughon, T. G. M.; Pena, R. S. Estudo da secagem da fibra residual do abacaxi. Alimentos e Nutrição, v.17, p.373-379, 2006.

Waughon, T. G. M.; Pena, R. S. S. Modelagem da secagem em camada delgada da fibra residual do abacaxi. Boletim do Centro de Pesquisa de Processamento de Alimentos, v.26, p.297-306, 2008. 